\title{
Penambahan Water Coolant Pada Cooling Tower Tipe Counter Flow
}

\author{
Achmad Zulfikar Zakawali ${ }^{1)}$, Suryo Widodo ${ }^{2)}$, Ali Akbar ${ }^{3)}$ \\ 1, 2, 3) Teknik Mesin, Universitas Nusantara PGRI Kediri \\ Email: ${ }^{1)}$ fikarzaka1@gmail.com
}

\begin{abstract}
Abstrak
Cooling tower adalah alat penukar kalor dengan fluida kerja air dan udara yang berfungsi mendinginkan air dengan kontak langsung dengan udara yang mengakibatkan sebagian kecil air menguap. Dalam kebanyakan cooling tower yang bekerja pada sistem pendinginan udara menggunakan pompa sentrifugal untuk menggerakkan air vertikal ke atas melintasi menara. Semua cooling tower yang bekerja akan melepaskan kalor melalui kondensor, refrigeran akan melepas kalornya kepada cooling tower sehingga air menjadi panas. Selanjutnya air panas ini akan dipompakan ke cooling tower. Dalam Penelitian ini peneliti akan menambahkan coolant yang kita tahu berfungsi sebagai pendingin. Tujuan penelitian ini adalah untuk mengetahui pengaruh penambahan water collant terhadap efektifitas pendinginan cooling tower. Penelitian terdahulu yang sudah pernah dilakukan adalah meneliti kinerja cooling tower dan efektifitas pendinginan cooling tower tersebut. Hasil penelitian diperoleh suhu awal air yang masuk ke cooling tower adalah $50{ }^{\circ} \mathrm{C}$ dan suhu air setelah diproses di colling tower tersebut adalah $40{ }^{\circ} \mathrm{C}$ untuk water coolant merk A, sedangkan untuk water coolant merk $B$ adalah $38{ }^{\circ} \mathrm{C}$. Dengan hasil ini dapat diketahui bahwa dengan penambahan coolant terhadap kinerja colling tower mempengaruhi efektivitas pendinginan cooling tower tersebut.
\end{abstract}

Kata Kunci: cooling tower, water coolant, efektivitas

\begin{abstract}
Cooling tower is a heat exchanger with water and air working fluid which functions to cool water by direct contact with air which causes a small portion of water to evaporate. In most cooling towers that work on air cooling systems use centrifugal pumps to move vertical water upward across the tower. All working cooling towers will release heat through the condenser, the refrigerant will release the heat to the cooling tower so that the water becomes hot. Furthermore, this hot water will be pumped to the cooling tower. In this study, researchers will add coolants that we know to function as coolants. The purpose of this study was to determine the effect of adding water coolants to the effectiveness of cooling rower. Previous research that had been conducted by Dian Morfi Nasution, (2010) entitled "Penelitian Kinerja Induced Draft Cooling Tower dengan Potongan Pipa Pvc Ø1 Inci Sebagai Filling Material" which examined the performance of cooling towers in the form of the effectiveness of cooling tower cooling. The results showed that the initial temperature of water entering the cooling tower was $50{ }^{\circ} \mathrm{C}$ and the temperature of the water after being processed in the cooling tower was $40{ }^{\circ} \mathrm{C}$ for water coolant brand $\mathrm{A}$, while for water coolant brand $\mathrm{B}$ was $38^{\circ} \mathrm{C}$. With these results it can be seen that the addition of coolants to the cooling tower performance affects the cooling effectiveness of the cooling tower.
\end{abstract}

Keywords: cooling tower, water coolant, effectivene 


\section{PENDAHULUAN}

Definisi dari cooling tower sebagai alat penukar kalor yang fluida kerjanya adalah air dan udara yang berfungsi mendinginkan air dengan kontak langsung dengan udara yang mengakibatkan sebagian kecil air menguap [1]. Dalam kebanyakan cooling tower yang bekerja pada sistem pendinginan udara menggunakan pompa sentrifugal untuk menggerakkan air vertikal ke atas melintasi menara. Semua cooling tower yang bekerja akan melepaskan kalor melalui kondensor, refrijeran akan melepas kalornya kepada cooling tower sehingga air menjadi panas [2]. Selanjutnya air panas ini dipompakan ke cooling tower. Cooling tower atau menara pendingin secara garis besar berfungsi untuk menyerap kalor dari air tersebut dan menyediakan sejumlah air yang relatif sejuk (dingin) untuk dipergunakan kembali di suatu instalasi pendingin atau dengan kata lain menara pendingin berfungsi untuk menurunkan suhu aliran air dengan cara mengekstraksi panas dari air dan mengemisikannya ke atmosfer.

Menara pendingin dapat mengatasi masalah tersebut di atas, karena mampu menurunkan suhu air lebih dari peralatan-peralatan yang hanya menggunakan udara untuk membuang kalor. Menara pendingin menurunkan suhu aliran air dengan cara mengektrasikan kalor dari air tersebut dan mengemisikannya ke atmosfir. Konsumsi air dari suatu sistem menara pendingin hanya sekitar 5\% dibandingkan dengan sistem pengaliran air sekali lewat yang telah disebutkan di atas, sehingga merupakan sistem yang paling ekonomis dari segi konservasi air. Selain itu, jumlah air panas yang terbuang (blow down) sangatlah kecil, sehingga efek terhadap ekologi juga sangat minim. Pada penelitian sebelumnya menyatakan bahwa water collant memiliki sifat yang dapat mempercepat penuruan suhu dari suatu zat atau cairan [3]. Untuk penelitian kali ini cooling tower akan ditambahkan dengan zat atau suatu cairan yang berfungsi sebagai media pemercepat penurunan suhu air di dalam cooling tower tersebut. Selain untuk mempercepat penuruan suhu zat atau cairan tersebut akan mengurangi beban kerja dari cooling tower terseburt dan untuk menekan biaya perawatan dari cooling tower itu sendiri.

Penambahan Water Coolant Pada Cooling Tower Tipe Counter Flow (Achmad Zulfikar Zakawali, Suryo Widodo, Ali Akbar) 


\section{METODE PENELITIAN}

Pada penelitian ini peneliti menggunakan metode eksperimental. Metode analisis menggunakan pengolahan analisa variasi (ANAVA) satu faktor dengan variasi penambahan coolant merk A dan coolant merk B.

\section{HASIL PENELITIAN}

a. Deskripsi Data Variabel

Deskripsi Data Variabel Bebas

Dalam Penelitian ini ada dua variabel terikat yaitu temperatur air keluar dan temperatur udara keluar setelah dilakukan penambahan water coolant. Dalam penelitian ini pengambilan data dilakukan selama 5 menit dalam setiap levelnya dan proses pengambilan data dilakukan berulang-ulang sebanyak enam kali untuk memperoleh data yang valid. Pengukuran temperatur air keluar menggunakan termometer yang yang dipasang di dalam penampungan air dingin dan tempat udara panas keluar. Hasil penelitian akan digambarkan sesuai tujuan hipotesis yang diajukan sebelumnya. Untuk Variabel bebas dapat digambarkan pada tabel berikut ini.

Tabel 3.1 Data hasil penelitian menggunakan air

\begin{tabular}{ccccccc}
\hline NO & $\begin{array}{c}\text { Variasi } \\
\text { Water } \\
\text { Collant }\end{array}$ & $\begin{array}{c}\text { T in } \\
\left({ }^{\circ} \mathrm{C}\right)\end{array}$ & $\begin{array}{c}\text { T out } \\
\left({ }^{\circ} \mathrm{C}\right)\end{array}$ & $\begin{array}{c}\text { Wet } \\
\text { Bulb } \\
\left({ }^{\circ} \mathrm{C}\right)\end{array}$ & $\begin{array}{c}\text { Debit Air } \\
(1 / \text { menit })\end{array}$ & menit \\
\hline 1 & & 50 & 45 & 27 & 15 & 5 \\
2 & & 50 & 43 & 27 & 15 & 5 \\
3 & & 50 & 39 & 27 & 15 & 5 \\
4 & Air & 50 & 43 & 27 & 15 & 5 \\
5 & & 50 & 44 & 27 & 15 & 5 \\
6 & & 50 & 42 & 27 & 15 & 5 \\
\hline
\end{tabular}

Tabel 3.2 Data hasil penelitian menggunakan coolant merk A

\begin{tabular}{llccccc}
\hline NO & $\begin{array}{l}\text { Variasi } \\
\text { Water }\end{array}$ & $\begin{array}{c}\text { T in } \\
\left({ }^{\circ} \mathrm{C}\right)\end{array}$ & $\begin{array}{c}\text { T out } \\
\left({ }^{\circ} \mathrm{C}\right)\end{array}$ & $\begin{array}{c}\text { Wet } \\
\text { Bulb } \\
\left({ }^{\circ} \mathrm{C}\right)\end{array}$ & $\begin{array}{c}\text { Debit Air } \\
(1 / \text { menit })\end{array}$ & menit \\
\hline 1 & & 50 & 45 & 35 & 27 & 5 \\
2 & & 50 & 43 & 35 & 27 & 5 \\
3 & & 50 & 42 & 35 & 28 & 5 \\
4 & merk A & 50 & 40 & 35 & 27 & 5 \\
\end{tabular}




\begin{tabular}{llllll}
5 & 50 & 39 & 35 & 27 & 5 \\
6 & 50 & 41 & 35 & 27 & 5 \\
\hline
\end{tabular}

Tabel 3.3 Data hasil penelitian menggunakan coolant merk B

\begin{tabular}{|c|c|c|c|c|c|c|}
\hline $\mathrm{NO}$ & $\begin{array}{l}\text { Variasi } \\
\text { Water } \\
\text { Collant }\end{array}$ & $\begin{array}{l}\mathrm{T} \text { in } \\
\left({ }^{\circ} \mathrm{C}\right)\end{array}$ & $\begin{array}{l}\text { T out } \\
\left({ }^{\circ} \mathrm{C}\right)\end{array}$ & $\begin{array}{l}\text { Wet } \\
\text { Bulb } \\
\left({ }^{\circ} \mathrm{C}\right)\end{array}$ & $\begin{array}{l}\text { Debit Air } \\
(1 / \text { menit })\end{array}$ & menit \\
\hline 1 & & 50 & 40 & 35 & 15 & 5 \\
\hline 2 & & 50 & 39 & 35 & 15 & 5 \\
\hline 3 & & 50 & 38 & 35 & 15 & 5 \\
\hline 4 & merk B & 50 & 41 & 35 & 15 & 5 \\
\hline 5 & & 50 & 40 & 35 & 15 & 5 \\
\hline 6 & & 50 & 38 & 35 & 15 & 5 \\
\hline
\end{tabular}

\section{b. Deskripsi Data Variabel Terikat}

Variabel terikat merupakan suatu variabel yang besarnya tidak dapat di tentukan sepenuhnya oleh peneliti, tetapi besarnya tergantung pada veriabel bebasnya. Variabel terikat pada penelitian kali ini adalah pemggunaan kisi 6 dan kinerja cooling tower yang berupa efektifitas pendinginan cooling tower.

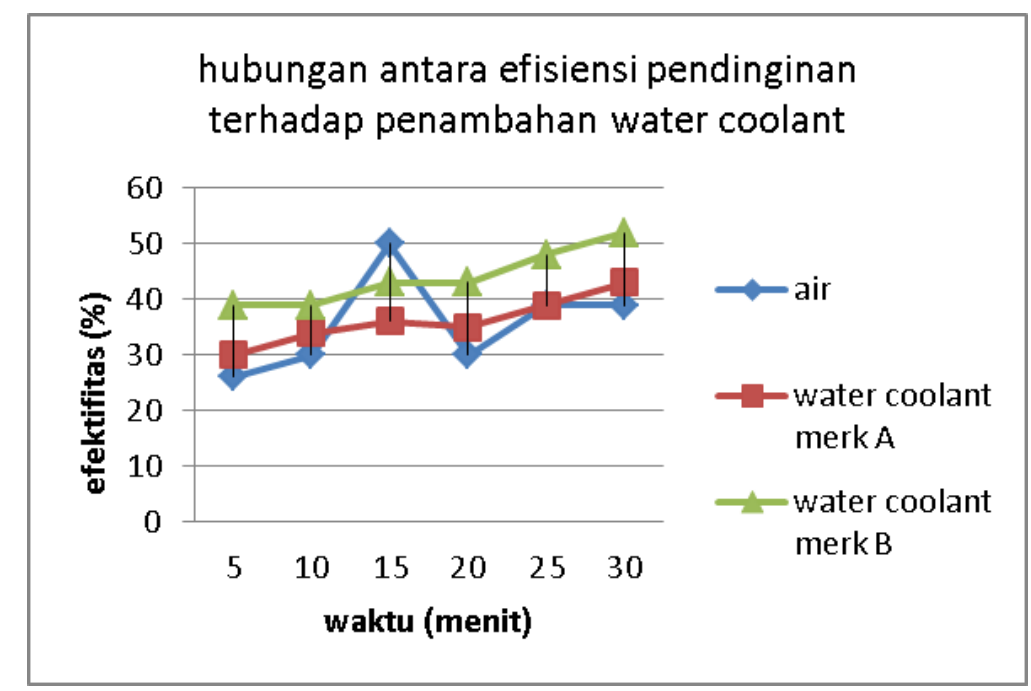

Gambar 3.1 Grafik efektifitas cooling tower

\section{c. Perhitungan Anava}

Dalam prosedur analisis data, perlu terlebih dahulu diuji dengan asumsi IIDN (identik, independen dan distribusi normal) untuk mengetahui apakah data 
variabel dalam keadaan baik atau tidak. Serta sebagai syarat dari Anova terhadap data yang didapat selama eksperimen.

Dalam prosedur analisis data, perlu terlebih dahulu diuji dengan asumsi IIDN (identik, independen dan distribusi normal) untuk mengetahui apakah data variabel dalam keadaan baik atau tidak. Serta sebagai syarat dari Anova terhadap data yang didapat selama eksperimen.

\section{d. Uji Kenormalan}

Uji kenormalan residual dilakukan dengan menggunakan uji AndersonDarling yang terdapat pada program minitab 16. Uji ini dilakukan untuk mengetahui apakah data variabel berdistribusi normal atau tidak. Penelitian menggunakan taraf signifikan kesalahan sebesar $\alpha=5 \%(0.05)$ dengan kata lain tingkat keyakinan sebesar $95 \%$.

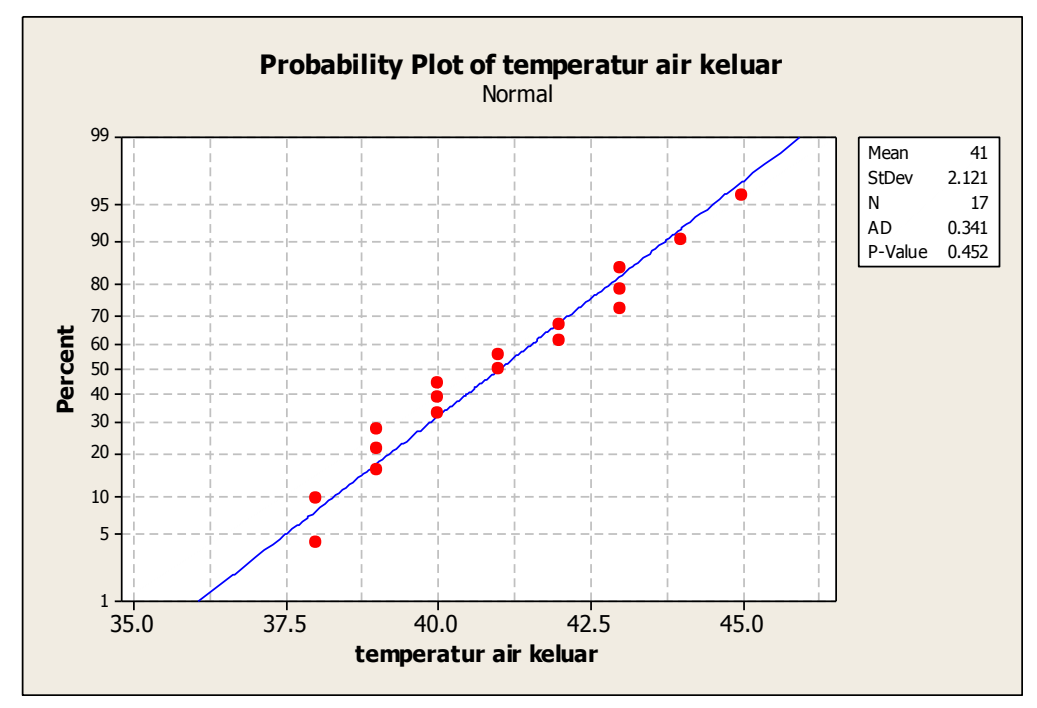

Gambar. 3.2 Plot Uji Distribusi Normal pada Respon Air Keluar

Dari plot uji distribusi diatas hipotesis yang digunakan adalah :

$\mathrm{H}_{0}$ : Residual berdistribusi normal

$\mathrm{H}_{1}$ : Residual tidak berdistribusi normal

$\mathrm{H}_{0}$ ditolak jika $p$-value lebih kecil dari pada $\alpha=0.05$. Gambar 3.1 menunjukkan bahwa dengan menggunakan uji Anderson-Darling Diperoleh $p$-Value pada pengujian temperatur air keluar sebesar 0,341. Maka $\mathrm{H}_{0}$ merupakan residual berdistribusi normal. 


\section{e. Uji Identik}

Setelah uji kenormalan kemudian uji identik untuk mengetahui apakah data penelitian yang dihasilkan identik atau tidak. Bila sebaran data pada output uji ini tersebar secara acak dan tidak membentuk pola tertentu disekitar harga nol maka data memenuhi asumsi identik. Namun bila output uji ini tersebar secara tidak acak dan membentuk pola tertentu disekitar harga nol maka data tidak memenuhi asumsi identik yang diperlukan

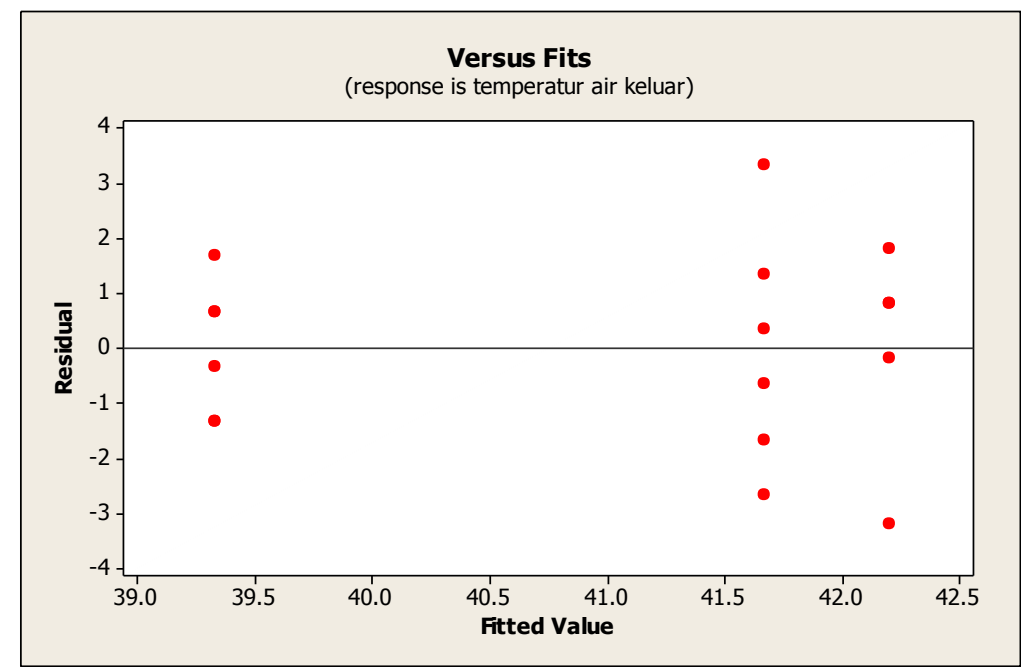

Gambar. 3.3 Plot Residual Pada Respon Temperatur Air Keluar Versus

\section{Fitted Values}

Pada gambar diatas menunjukkan bahwa pengujian nilai temperatur air keluar memiliki residual tersebar secara acak disekitar harga nol dan tidak membentuk pola tertentu. Dengan demikian asumsi residual identik terpenuhi.

\section{f. Uji Independen}

Pengujian independen pada penelitian ini dilakukan dengan menggunakan auto correlation function (ACF) yang terdapat pada program minitab 16. Pengujian ini untuk mengetahui apakah terdapat nilai ACF yang keluar dari batas interval atau tidak. Bila tidak terdapat nilai yang melebihi batas interval maka data penelitian ini memenuhi asumsi independen, namun bila terdapat data penelitian yang melebihi batas interval maka terdapat hasil pengukuran yang terpengaruh oleh hasil pengukuran lainnya. 


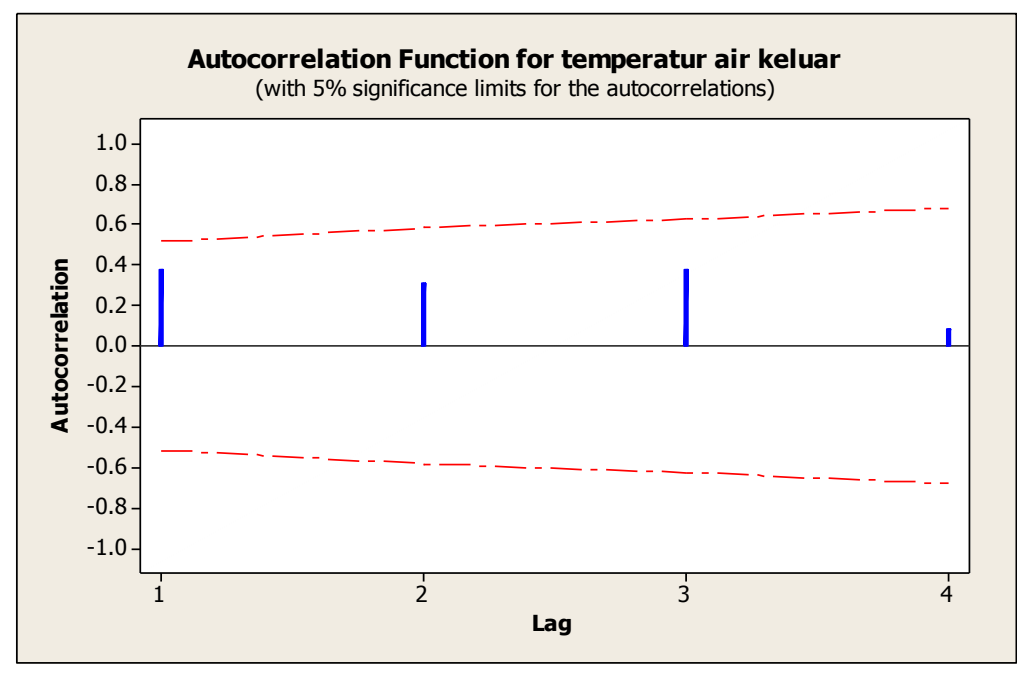

Gambar 3.4 Plot ACF Pada Respon Temperatur Air Keluar

Berdasarkan plot ACF yang ditunjukkan pada gambar diatas tidak ada nilai ACF pada lag yang keluar dari batas interval. Hal ini membuktikan bahwa tidak ada kolerasi antar residual artinya bersifat independen.

\section{g. Analisis Variasi (ANAVA)}

Setelah uji identik, independen dan distribusi normal terpenuhi dilakukan analisis variasi. Tujuannya adalah untuk mengetahui variabel proses mana yang memiliki pengaruh secara signifikan terhadap efektifitas pendinginan cooling tower.

\section{KESIMPULAN}

Berdasarkan hasil eksperimen dan analisis data yang telah dilakukan, maka dapat diambil keimpulan bahwa dengan penambahan water coolant ke cooling tower berpengaruh terhadap kinerja cooling tower.

\section{DAFTAR PUSTAKA}

[1] Johanes S. "Karakteristik Menara Pendingin dengan Bahan Isian Ijuk". Forum Teknik. 33 (3), 188-194. 2010.

[2] Yulianto Sulis, Urbiantoro Aan. Perancangan Cooling Tower Untuk Alat Penukar Kalor Shell and Tube Kapasitas Skala Laboratorium. Sintek. Volume 7 No.1. 
[3] Mahendran, Mukund . Muralidharan. Design and Fabrication of Mini Draft Cooling Tower. K. Ramakrishnan college of Technology. Samayapuram, Trichy. Tamilnadu, India. 2016.

[4] Naustion, D.M. "Penelitian Kinerja Induced Draft Cooling Tower dengan Potongan Pipa Pvc $\varnothing 1$ Inchi Sebagai Filling Material”. Skripsi. Departemen Teknik Mesin Universitas Sumatra Utara. 2010.

[5] Pratiwi N.P., Nugroho G., Hamidah N.L. "Analisa Kinerja Cooling Tower Induced Draft Tipe Lbc W-300 Terhadap Pengaruh Temperatur Lingkungan”, Jurnal Teknik Pomits, 7 (7). 2014. 